\title{
Saberes docentes nas Licenciaturas em Computação: análise de projetos pedagógicos de cursos
}

\author{
Adão Caron Cambraia ${ }^{1}$, Márcia Adriana Rosmannn ${ }^{1}$, Pauleany Simões de Morais ${ }^{2}$, \\ Pietro Matheus Bompet Fontoura Alves ${ }^{3}$, Uianes Luiz Rockenbach Biondo ${ }^{4}$ \\ ${ }^{1}$ Instituto Federal de Educação, Ciência e Tecnologia Farroupilha (IFFar) \\ ${ }^{2}$ Instituto Federal de Educação, Ciência e Tecnologia Rio Grande do Norte (IFRN) \\ ${ }^{3}$ Universidade Federal da Bahia (UFBA) \\ ${ }^{4}$ Universidade Federal de Santa Maria (UFSM) \\ \{adao.cambraia, marcia.rosmann\} eiffarroupilha.edu.br, paule- \\ any.morais@ifrn.edu.br, pietro.bompet@ufba.br, biondouianes@gmail.com
}

\begin{abstract}
The paper aims to analyze the conceptions of teaching knowledge in the Pedagogical Course Projects (PPC) of Computer Science Degree (LC) in the states of Rio Grande do Sul, Santa Catarina, Paraná, and Bahia. The courses and states were chosen according to the performance of the authors in these regions and documentary research were used as a methodological approach. The analysis was carried out from seven PPC, using Content Analysis, in order to contemplate: pre-analysis; exploration of the material; and treatment of results. The results show a lack of theoretical references and questions about knowledge.

Resumo. $O$ artigo visa analisar as concepções de saberes docentes nos Projetos Pedagógicos de Cursos (PPC) de Licenciatura em Computação (LC) dos estados do Rio Grande do Sul, Santa Catarina, Paraná e Bahia. Os cursos e estados foram escolhidos conforme a atuação dos autores nessas regiões e utilizou-se a pesquisa documental como encaminhamento metodológico. A análise foi realizada a partir de sete PPC, utilizou-se a Análise de Conteúdo, de modo a contemplar: pré-análise; exploração do material; e tratamento de resultados. Os resultados apresentam escassez de referências teóricas e problematizações sobre os saberes.
\end{abstract}

\section{Reflexões Iniciais}

Os saberes docentes nos cursos de Licenciatura em Computação (LC) são a temática abordada neste estudo, que busca elucidar a problemática "Quais as concepções sobre saberes docentes presentes nos Projetos Pedagógicos de Curso (PPC) de Licenciaturas em Computação?". O texto foi proposto após a realização da revisão sistemática da literatura, em que analisamos os saberes docentes em publicações do Workshop da Licenciatura em Computação nos anos de 2017, 2018 e 2019 (Cambraia, Morais \& Oliveira, 2020). Nessa publicação foram constatadas a inexpressiva quantidade de trabalhos acerca dos saberes docentes na formação inicial de professores de Computação, constituindo-se como indício de que os professores valorizam mais os conhecimentos da Computação e que a categoria saberes docentes não é levada em consideração nas reflexões dos professores. Assim, ao identificar as concepções 
referentes aos saberes docentes nos PPC visamos problematizar, discutir e ampliar as pesquisas sobre o referido campo de estudo.

Para a localização dos PPC, acessamos o portal do E-Mec (https://emec.mec.gov.br) e procuramos as instituições que possuem a LC cadastrada nos estados do Rio Grande do Sul, Santa Catarina, Paraná e Bahia. Na região Sul do Brasil foram localizadas 16 instituições cadastradas que oferecem ou ofereceram o curso. Em algumas instituições, como é o caso da Universidade Estadual de Londrina (UEL), a oferta ocorre em sete municípios num total de 367 vagas. Das dezesseis instituições ofertantes, em cinco o curso está em extinção (UNOESC, UNILASSALE, UNIJUÍ, UCS, UDESC) e uma instituição (UNISC) aparece no status como curso Não Iniciado. As demais instituições aparecem como em atividade, sendo em Educação a Distância (EAD) seis instituições (UEL, UNESA, UNISC, UFSM, CENTRO UNIVERSITÁRIO ESTÁCIO DE SANTA CATARINA e UNOESC). As demais ofertam na modalidade presencial (FURB, UNISC, UFPR, IFSUL, IFFAR, UNICNEC). No estado da Bahia foram localizadas cinco instituições que oferecem a LC, todos com o status de ativo, onde três deles são ofertados na modalidade presencial (IFBA, UFBA e Universidade Salgado de Oliveira - UNIVERSO) e mais três na modalidade EAD (IFBA, Centro Universitário Claretiano - CEUCLAR e Universidade Estácio de Sá UNESA). No caso do IFBA, a oferta ocorre no formato de polos, em dois municípios atendendo duas regiões diferentes do estado. Duas instituições (UNIVERSO e UNESA) não disponibilizam o PPC nos sites.

Foram incluídos na análise os $\mathrm{PPC}^{1}$ das instituições que disponibilizam na internet e possuem cursos ativos. Das instituições da Região Sul ofertantes foram analisados: UFPR, UFSM, IFSUL, IFFAR. No estado da Bahia, foram analisados do IFBA, UFBA e CLARETIANO. A partir da análise inicial, evidenciamos a presença de componentes curriculares de conhecimentos específicos da Ciência da Computação (Algoritmos, Estrutura de dados, Sistemas Operacionais e outras) e conhecimentos específicos da Pedagogia e as práticas profissionais (práticas como componente curricular e estágios). Geralmente, nos PPC são destacados a articulação entre saberes da Computação e Pedagógicos.

Inicialmente, desenvolvemos uma pesquisa com referencial teórico sobre os saberes docentes a partir de Tardif (2000, 2012) e Gauthier (2013). Como encaminhamento metodológico, nos ancoramos na pesquisa bibliográfica e documental (Gil, 2002) em que analisamos os Projetos Pedagógicos de Cursos de LC, de modo a compreender como a temática tem sido pensada no momento de elaboração dos cursos. Especificamente para análise dos resultados foi utilizada a Análise de Conteúdo (AC) conforme os estudos de Bardin (2016), sendo organizada a partir de três fases: 1) préanálise; 2) exploração do material; 3) tratamento dos resultados e interpretação em categorias temáticas a partir dos saberes elencados por Tardif (2000). Na pré-análise, realizou-se a leitura "flutuante" e a escolha do universo de documentos (PPC) a serem submetidos a análise, com base nas regras da exaustividade, representatividade, homogeneidade e pertinência (Bardin 2016, p. 126-128), constituindo assim o corpus de análise. $\mathrm{Na}$ etapa de escolha dos índices e elaboração dos indicadores, realizamos uma leitura prévia dos PPC e a busca com a utilização das palavras-chave "formação

\footnotetext{
${ }^{1}$ Importante destacar que enviamos e-mails para todos os coordenadores de cursos requisitando os PPC e obtivemos retorno apenas da UFSM.
} 
profissional"2 e "saberes", de modo a compreendermos as concepções e, em seguida, categorizamos, de modo a contemplar os saberes: profissionais, disciplinares/curriculares, experienciais e pedagógicos.

O texto está construído em três sessões, conforme descrito a seguir: i) discussão teórica acerca dos saberes docentes; ii) análise dos PPC da LC no Brasil, especificamente de estados da Bahia, Paraná, Rio Grande do Sul e Santa Catarina; iii) reflexões finais sobre a constituição dos saberes docentes e, consequentemente, das identidades dos professores de Computação.

\title{
2. Constituição dos Saberes Docentes: alguns referenciais
}

Durante a formação inicial docente, elementos fundamentais e constituintes da profissão devem ocasionar a construção do verdadeiro sentido da Educação como práxis transformadora da realidade dos sujeitos envolvidos. Para Tardif (2000, p. 10), a epistemologia da prática profissional é "o estudo do conjunto dos saberes utilizados realmente pelos profissionais em seu espaço de trabalho cotidiano para desempenhar todas as suas tarefas". Para o autor, o amálgama de saberes (conhecimentos, competências, habilidades/aptidões, atitudes) é o saber-fazer e o saber ser do professor. Desse modo,

\begin{abstract}
A finalidade de uma epistemologia da prática profissional é revelar esses saberes, compreender como são integrados concretamente nas tarefas dos profissionais e como estes os incorporam, produzem, utilizam, aplicam e transformam em função dos limites e dos recursos inerentes às suas atividades de trabalho. Ela também visa a compreender a natureza desses saberes, assim como o papel que desempenham tanto no processo de trabalho docente quanto em relação à identidade profissional dos professores. (Tardif, 2000, p. 11).
\end{abstract}

Tardif (2012, p. 54) define o significado do saber docente como "saber plural, formado de diversos saberes provenientes das instituições de formação, da formação profissional, dos currículos e da prática cotidiana”. Nesse sentido, é essencial na construção dos saberes docentes uma formação qualificada em instituições educacionais, que mobilizem conhecimentos aos atos de ensinar. $\mathrm{O}$ autor delimita uma caracterização construída a partir dos próprios docentes e dos saberes que eles utilizam, de forma afetiva em sua prática, quais sejam: saberes da formação profissional voltados às ciências da educação (teorias e métodos); saberes disciplinares (referentes aos saberes em cada área do conhecimento); saberes curriculares (selecionados e categorizados pelas instituições escolares); e saberes experienciais (constituídos em sua essência na base do trabalho cotidiano). Quando se trata da práxis docente, deve-se preparar um profissional considerando sua dimensão científica, técnica, tecnológica, pedagógica, cultural e humana, ou seja, uma formação omnilateral. "É preciso, portanto, que a pesquisa universitária se apoie nos saberes dos professores a fim de compor um repertório de conhecimentos para a formação de professores" (Tardif, 2000, p. 11-12). Por isso, destacamos a necessidade de problematizar os saberes docentes para que professores em formação possam compreender, produzir, transformar e registrar sobre a profissão docente.

A partir desse contexto, Gauthier (2013) descreve uma pedagogia voltada aos

\footnotetext{
${ }^{2}$ Dificilmente, se encontra o excerto "saberes" nos PPC, então, para saberes profissionais na formação docente selecionamos o excerto "formação profissional".
} 
seres humanos enquanto sujeitos do diálogo e da reciprocidade na constituição dos saberes à ação docente. Em seu livro Por uma teoria da Pedagogia, Gauthier (2013) compreende o ensino como uma prática instigante e criadora de muitos saberes, os quais constituem a profissão do professor, e são possibilidades de refletir as problemáticas de situações advindas da atuação docente. Dentre os saberes a serem desenvolvidos na práxis docente, o autor destaca o saber relacionado à ação pedagógica - saber experiencial segundo Tardif $(2000,2012)$, em que trata das possibilidades e processos decisórios cotidianos que conduzem o exercício do magistério, com a criação de um "ofício feito de saberes". Para o autor, o professor constituído por um "ofício feito de saberes" é um

[...] profissional, ou seja, como aquele que, munido de saberes e confrontando a uma situação complexa que resiste à simples aplicação dos saberes para resolver a situação, deve deliberar, julgar e decidir com relação à ação a ser adotada, ao gesto a ser feito ou à palavra a ser pronunciada antes, durante e após o ato pedagógico (Gauthier, 2013, p. 331).

Refletir sobre a constituição dos saberes docentes na trajetória de formação de suas vivências acadêmicas e, a posteriori, na condição de professor atuante é condição sine qua non para a constituição docente, ou seja, é a conscientização de que para ser professor o conhecimento da computação é fundamental, mas não suficiente. Nesse sentido, o saber profissional do professor não é único, por isso é considerado saberes no plural, diante de suas múltiplas dimensões, articulados. Dessa forma, entendemos que os estudos aos quais contemplem os saberes docentes devem estar presentes na formação inicial de professores, considerando as dimensões sociais, políticas, culturais e pedagógicas. No próximo tópico, analisamos como os saberes docentes são apresentados nos PPC de diferentes LC.

\section{Saberes Docentes nos Projetos Pedagógicos das Licenciaturas em Computação}

Foram considerados como documentos de análise os sete PPC das diferentes instituições de Educação, já descritas nas Reflexões Iniciais. A partir da leitura do material, utilizamos as palavras-chave "formação profissional" e "saberes" que poderiam indicar a presença dos saberes profissionais docentes, resultando na categorização dos PPC a partir das dimensões apresentadas a seguir: (FP) Formação Profissional, (D) saberes disciplinares, (C) Curriculares, (E) Experienciais e (P) Pedagógicos. A partir do exposto, a tabela 1 apresenta a sistematização realizada durante a etapa de análise, o "X" apresenta a ocorrência do termo e "Não" representa que não houveram resultados relacionados na busca.

Tabela 1 - Saberes Docentes em PPC da Licenciatura em Computação

\begin{tabular}{|c|c|c|c|c|c|c|}
\hline \multirow{2}{*}{ Estados } & Instituições (modalidades) & \multicolumn{5}{|c|}{ Saberes } \\
\cline { 2 - 7 } & & FP & D & C & E & P \\
\hline \multirow{2}{*}{ BA } & IFBA (Presencial e EAD) & $X$ & $X$ & $X$ & $X$ & $X$ \\
\cline { 2 - 7 } & UFBA (Presencial) & Não & $X$ & $X$ & Não & Não \\
\cline { 2 - 7 } & Claretiano (EAD) & $X$ & $X$ & Não & Não & $X$ \\
\hline \multirow{2}{*}{ PR, SC e } & IFFar (Presencial) & $X$ & $X$ & $X$ & $X$ & $X$ \\
\hline
\end{tabular}




\begin{tabular}{|c|c|c|c|c|c|c|}
\hline \multirow{3}{*}{ RS } & UFSM (EAD) & $X$ & Não & $X$ & Não & $X$ \\
\cline { 2 - 7 } & UFPR (Presencial) & $X$ & Não & $X$ & Não & $X$ \\
\cline { 2 - 7 } & IFSul (Presencial) & $X$ & $X$ & $X$ & Não & $X$ \\
\hline
\end{tabular}

Fonte: Elaborado pelos autores conforme os PPC analisados, 2020.

Importante destacarmos que os saberes curriculares não são referenciados diretamente nos PPC, no entanto, como todos os cursos são de formação de professores de Computação há uma atenção especial aos conceitos da área, por isso, marcamos como presente no PPC. Da mesma forma para outros saberes que a leitura nos possibilitou interpretar sua presença, como veremos na análise dos excertos que segue.

A palavra-chave que aparece com mais frequência nos PPC das LC é "formação profissional", propondo a interlocução entre a formação pedagógica e os conhecimentos específicos da Ciência da Computação. No PPC da UFSM percebe-se a concepção de que cada LC precisa adquirir identidade própria de acordo com as características da comunidade em que se insere, priorizando uma articulação de saberes docentes entre a Pedagogia e Computação. Vale salientar que no PPC citado há uma ênfase dada a concepção da formação profissional no curso de Licenciatura.

\begin{abstract}
A formação profissional da licenciatura deverá adquirir identidade própria e integrar a formação pedagógica e a formação específica. Tais pressupostos exigem dos alunos e docentes, durante todo o percurso da formação, uma atitude ativa e reflexiva sobre a prática, os currículos e conteúdos apresentados e sobre o processo de aprendizagem, estabelecendo-se dinâmicas pedagógicas diferenciadas e próprias daquelas desenvolvidas na prática dos cursos de bacharelado (Ufsm, 2015, s/n, grifo nosso).
\end{abstract}

Ao pensarmos na formação do sujeito professor e a dimensão pedagógica, no curso de LC, não basta apenas acrescentar componentes curriculares da Ciência da Educação (presentes no curso de Pedagogia) em conjunto com componentes curriculares específicos (que geralmente compõe um bacharelado) e sim, a necessidade de reflexões e atitudes articuladas com a formação que fomente a autonomia e responsabilidade, representando uma profissionalidade do professor, que

[...] se reivindica maior e melhor formação, capacidade para enfrentar novas situações, preocupação por aspectos educativos que não podem ser descritos em normas, integridade pessoal, responsabilidade naquilo que faz, sensibilidade diante de situações delicadas, compromisso com a comunidade etc. Essas exigências oferecem um caráter muito especial ao sentido de qualificação ou autonomia para os docentes. [...] Autonomia, responsabilidade, capacitação são características tradicionalmente associadas a valores profissionais que deveriam ser indiscutíveis na profissão docente (Contreras, 2012, p. 80-81).

Nesse sentido, para a constituição da profissionalidade docente, necessita-se de uma formação mais humana pautada na responsabilidade, guiada pelos princípios da alteridade, equidade, autonomia e ética. Atenta-se para as vivências e as especificidades dos sujeitos envolvidos no ato pedagógico, de forma a articular movimentos que promovam essas características e orientações para o exercício da docência. Busca-se portanto a construção de saberes docentes articulados com os contextos envolvidos e os conhecimentos curriculares (pré-escritos e praticados).

A formação inicial docente orientada pelo planejamento colaborativo, desenvolvimento de vivências nos contextos de atuação e constituição de atividades a 
partir do olhar sensível dos sujeitos partícipes para a promoção das aprendizagens, que devem ser sistematizadas ao longo do curso. Os momentos de iniciação a docência do professor em formação na Educação Básica, oportunizados durante os componentes curriculares, a exemplo de Estágio Supervisionado e Prática de Ensino, devem promover reflexões para constituir saberes docentes e superar um modelo positivista de formação. Pesquisas sobre temas de relevância social para vivenciar a complexidade do mundo contemporâneo ganharam notoriedade, como se evidencia no excerto selecionado no PPC do IFFAR.

\begin{abstract}
O acadêmico deverá construir conceitos de formação profissional de professores por meio de pesquisas de temas atuais e de relevância social, conforme necessidade apresentada por alunos e professores de maneira a contribuir com a qualidade dos futuros docentes, bem como, pesquisar, analisar e discutir assuntos atuais, contextualizando o ensino da informática com vistas à melhoria da qualidade do trabalho do professor para atender as demandas do mundo contemporâneo (Iffar, 2014, p. 39).
\end{abstract}

O trecho anterior evidencia ainda a limitação teórica-epistemológica da área da Computação ao ser reduzida a apenas "Informática" na descrição do campo de formação profissional, mesmo compreendendo a potência da formação relacionado aos contextos cotidianos. Ressalta-se que o curso de LC é, intrinsecamente, interdisciplinar a partir da relação entre a Matemática, Educação e Ciência da Computação, mas a construção de saberes para atuação e vivência na sociedade contemporânea exige do profissional em formação um processo constante de reflexão-ação, reflexão sobre a reflexão na ação (Schön, 1992).

No PPC do IFSUL, a ênfase a formação profissional, é caracterizada pela formação integral, omnilateral, que não segrega a formação inicial do professor nas áreas do conhecimento, seja na Educação ou Ciência da Computação, com contextos de vivências profissionais.

A estrutura curricular do curso visa o desenvolvimento de competências e habilidades necessárias ao futuro professor através do aprendizado na perspectiva da interface e da transversalidade possíveis de diversos campos de saberes e das tecnologias a eles correspondentes, com vista à formação da cidadania universal e da formação profissional. Ao longo do curso serão desenvolvidos gradualmente habilidades e conhecimentos necessários à formação do licenciado em Computação (Ifsul, 2018, p. 11).

A articulação entre os diferentes saberes docentes e as tecnologias também é destaque no PPC citado, com ênfase para práticas a partir de competências e habilidades. Esses saberes em destaque são estudados por Koelher \& Mishra (2008) e denominados de Conhecimento Tecnológico Pedagógico do Conteúdo. No campo do estudo e desenvolvimento das tecnologias contemporâneas, o licenciando necessita se apropriar dos conhecimentos para além dos processos de instrumentalização e, assim, compreender a importância dessas a partir das necessidades e fenômenos sociais. Com a superação desse processo, a transposição didático-pedagógica no ensino da Computação poderá ser significativa diante das necessidades e realidades sociais.

Ao investigar os PPC do IFBA, na modalidade EAD e presencial, os saberes necessários à formação profissional (saberes profissionais) aparecem no perfil do egresso como "saberes, teorias e representações" (Ifba, 2015) e em um objetivo específico. Os saberes são apresentados no texto como resultantes dos conhecimentos mobilizados ao longo da trajetória de formação inicial (saberes experienciais). Além 
disso, o saber é compreendido como elemento constituinte da mediação docente, contemplando aspectos que incidem sobre a práxis do professor, caracterizando como saber plural (Tardif, 2012).

Saber plural, saber formado de diversos saberes provenientes de formação, da formação profissional, dos currículos e da prática cotidiana, o saber docente é, portanto, essencialmente heterogêneo. Mas, essa heterogeneidade não se deve apenas à natureza dos saberes presentes; ela decorre também da situação do corpo docente diante dos demais grupos produtores de saberes e das instituições de formação (Tardif, 2012, p. 54).

Ao observar a referência aos saberes disciplinares no currículo pré-escrito da LC, nota-se que são apresentados a partir do estudo nos ambientes formais de Educação (como a escola) e das relações socioculturais e utilizados como bases fundamentais para a argumentação, apresentando que a "[...] maior objetivação dos conteúdos analisados e permite que o educando não sinta que aprende algo abstrato ou fragmentado." (Ifba, 2015, p. 48), mas apresenta a estruturação dos componentes curriculares centrados na perspectiva disciplinar.

No PPC da instituição da rede privada Claretiano, constatamos a escassez dos termos "saberes" ou "formação profissional", pois ambos aparecem de maneira superficial em uma reflexão sobre o papel social da universidade na perspectiva da constituição de sua historicidade.

\begin{abstract}
A universidade conserva, memoriza, integra e ritualiza uma herança cultural de saberes, ideias e valores, que acaba por ter um efeito regenerador, porque a universidade se incumbe de reexaminá-la, atualizá-la e transmiti-la. (ao mesmo tempo em que) gera saberes, ideias e valores, que, posteriormente, farão parte dessa mesma herança. (Claretiano, 2017, s/n, grifo nosso).
\end{abstract}

Ao tratar sobre saberes no perfil do egresso, o documento anterior caracteriza os conhecimentos necessários a iniciação à docência de forma descontextualizada do processo de ensino e aprendizagem. Inferimos que o perfil do egresso da LC precisa contemplar a constituição dos saberes docentes, articulados com as aprendizagens dos alunos da Educação Básica, do objeto do conhecimento da área de formação e os conhecimentos didático-pedagógicos, sendo, portanto, fundamentos intrínsecos a formação do professor de Computação.

Ainda observa-se no PPC da Claretiano o destaque para a concepção de universidade como espaço de promoção de práticas na perspectiva do Exame, reduzindo-a ao processo de "transmissão" de saberes, ao contrário da necessidade e compromisso social para construção coletiva e promoção de saberes imbricados nos cursos de formação, especialmente as licenciaturas. A respeito do sujeito egresso da LC,

O educador formado no curso de Licenciatura em Computação deve ser um profissional que incorpore competências, saberes e habilidades de criatividade, de inovação, de cooperação, de trabalho em equipe, de gestão, de tomada de decisões, de aquisição e produção de conhecimentos, de expressão e comunicação, não sendo somente reprodutor de conhecimentos já estabelecidos (Claretiano, 2017, p. 63)

Ao analisar o PPC da UFBA, constatamos a citação do termo saberes em dois momentos. No primeiro, o termo é abordado na ementa de um componente curricular vinculado a Faculdade de Educação e desconsidera os saberes constituídos ao longo da formação. $\mathrm{Na}$ segunda menção, o termo é caracterizado a partir da tentativa de superação do modelo transmissível do conhecimento, além de apresentar limitações 
acerca dos referenciais teórico-metodológicos necessários para a formação de professores.

Conhecendo as dificuldades epistemológicas dos alunos espera-se desenvolver ações transformadoras para alcançar mudanças pessoais e coletivas, e para a transposição do modelo da transmissão e memorização de informações, para um modelo de construção coletiva de conhecimentos robustos e saberes duradouros (Ufba, 2010, p. 1)

São diversas as questões que permeiam a condução de um PPC, particularmente em LC, pois deveriam buscar a consolidação de uma formação de professores a partir de projetos de democratização e transformação nos diversos níveis e modalidades de Educação. Constata-se a ausência de fundamentos da Educação com articulação com a Ciência da Computação, de forma a comprometer a constituição do perfil dos licenciandos, perpetuando a permanente divisão das áreas do conhecimento.

No PPC do IFFAR há menções acerca dos saberes docentes, a partir dos termos formação profissional, saberes pedagógicos, disciplinares, curriculares, experienciais. A referenciação desses saberes no PPC do IFFAR pode ser justificado em decorrência da existência de um componente curricular denominado "Saberes docentes e formação continuada" 3 . A ementa traz referências pontuais acerca dos tópicos abordados, de forma a demarcar um território de estudos e problematizações sobre saberes docentes.

O saber docente. Saberes da Formação profissional. Saberes disciplinares. Saberes Curriculares. Saberes Experienciais. Saberes da Ação Pedagógica. Construção identitária e saberes docentes. Teorias da Formação de professores. Formação continuada em serviço (Iffar, 2014, p. 85).

$\mathrm{Na}$ ementa anterior é possível evidenciar a categorização dos saberes docentes elencados no texto e pautados em Tardif (2014) e Gauthier (2013), o que pode representar um espaço de possibilidades de estudos sobre a temática. De toda forma, é importante ressaltar que não se trata de uma apologia a criação de componentes curriculares que abordem os saberes, até porque nos PPC dos cursos investigados (UFSM, UNESA, UFPR, IFSul, IFBA e UFBA), os saberes docentes são tratados de forma transversal e perpassam desde estudos disciplinares, estágios supervisionados e práticas de ensino de Computação. Na UFPR, Tardif (2014) é utilizado como bibliografia básica em três componentes curriculares. Assim, se constituiu uma integração de saberes profissionais, como pode ser evidenciado na descrição da prática profissional do IFSul:

[...] A prática figura tanto como propósito formativo, quanto como princípio metodológico, reforçando, ao longo das vivências curriculares, a articulação entre os fundamentos teórico-conceituais e as vivências profissionais, com ênfase no domínio dos princípios didáticos-pedagógicos indispensáveis ao ofício docente (Ifsul, 2018, p. 14).

Com isso, entende-se que a prática profissional ${ }^{4}$ constitui-se como alternativa para proporcionar reflexões sobre o pensar/fazer docente, com possibilidades de desenvolvimento de práticas envolvendo os espaços da Educação Básica desde o

\footnotetext{
${ }^{3}$ É um componente curricular ofertado no $8^{\circ}$ semestre da LC e possui a carga horária total de 72 horas.

${ }^{4} \mathrm{Na}$ prática profissional há flexibilidade para a organização das ações pedagógicas, possibilitando um exercício do trabalho coletivo (colegiados de cursos) para pensar/escrever a proposta no PPC e depois desenvolver de forma integrada com a comunidade local, proporcionando um amálgama de saberes docentes de professores de computação de forma contextualizada.
} 
primeiro semestre do curso, rompendo com a lógica mecanicista que desarticula teoria e prática. Nesse contexto, é evidenciado a produção de saberes na prática profissional pelo planejamento colaborativo, desenvolvimento e avaliação de projetos integradores (Cambraia \& Zanon, 2018), que conforme os autores, as práticas podem incentivar a produção de saberes docentes nos cursos de formação de professores. Com isso, destacamos que os PPC dos cursos de LC carecem de reformulações que proporcionem a reflexão sobre o fazer/ser professor para constituir saberes docentes.

\section{Reflexões Finais}

Em linhas gerais, os PPC analisados deveriam enfatizar os movimentos de constituição dos saberes docentes nas diversas sessões, especialmente quando o foco da escrita refere-se ao perfil do egresso. Foi evidenciado que a grande maioria dos cursos de LC no Brasil não contemplam em seus documentos oficiais discussões acerca dos saberes docentes, bem como foi constatado a restrita menção de componentes curriculares específicos que permitam a discussão sobre a formação docente. Se constitui como fundamental a ampliação de estudos sobre a mobilização de saberes imbricados no transcurso da formação para a docência. Com isso, ressaltamos a necessidade histórica de (re)elaboração dos PPC dos cursos de formação inicial de professores na área da Computação. Soma-se a este contexto, a constatação acerca da indisponibilidade e/ou não veiculação de reformulações aos PPC, originalmente criados a partir do ano de 2010 com a expansão da oferta de vagas em cursos de LC no Brasil, mesmo após a obrigatoriedade de atendimento a Resolução $\mathrm{n}^{0}$ 02/2015 (Brasil, 2015), como evidenciamos em um PPC analisado.

Entendemos que a problematização acerca dos saberes e fazeres durante a formação de professores de Computação se configura como desafio, diante da constatação da investigação a partir da ausência de menções e/ou articulações para a constituição dos saberes disciplinares, curriculares, experienciais e pedagógicos. Desse modo recorremos a uma busca mais ampla, com os termos "formação profissional" e "saberes" e percebemos diferentes concepções, como: 1) articulação entre conhecimentos pedagógicos e curriculares, em diferentes contextos, constituindo um amálgama de saberes (geralmente nos PPC acabam referenciando apenas a importância de conhecimentos da computação e pedagógicos); 2) planejamento colaborativo, desenvolvimento e avaliação das ações desenvolvidas como uma forma de desenvolvimento de saberes docentes; 3) relacionar a formação inicial com problemas cotidianos das escolas de Educação Básica; 4) Reflexão na ação e reflexão sobre a reflexão na ação, que pode ocorrer em processos de escrita como este texto.

A partir da análise aqui realizada, espera-se que a comunidade de professores em formação e em atuação na área de Educação em Computação possam proporcionar uma formação, que contemple reflexões sobre saberes docentes com novos encaminhamentos ao estudo aqui abordado, de modo a repensar o percurso formativo dos futuros professores de Computação, por meio de reformulações de PPC das LC. Para pesquisas futuras, sugerimos desenvolver entrevistas com professores de Computação para compreender as concepções do movimento da constituição dos saberes docentes na sua prática pedagógica. 


\section{Referências}

Brasil. (2015). Resolução CNE/CP $n^{o}$ 2, de 1 de julho de 2015. Disponível em: http://portal.mec.gov.br/index.php?option=com_docman\&view=download\&alias $=13$ 6731-rcp002-15-1\&category_slug=dezembro-2019-pdf\&Itemid=30192, Acesso em 02 set. 2020

Cambraia, A. C.; Zanon, L. B. (2018). Desenvolvimento Profissional Docente numa Licenciatura: interlocuções sobre o projeto integrador. In: Revista Brasileira de Educação, v.23. Doi: https://doi.org/10.1590/s1413-24782018230043

Cambraia, A. C.; Morais, P. S.; OLIVEIRA, W. (2020). Saberes docentes: desafios na Licenciatura em Computação. In: CRUZ, G. B.; GABRIEL, C. T.; VASCONCELLOS, M. AZEVEDO, P. B. Livro 1 - Didática(s) entre diálogos, insurgências e políticas. XX ENDIPE - Encontro Nacional de Didática e Práticas de Ensino.| Rio, 2020.

Claretiano. (2017). Projeto Pedagógico de Curso - Licenciatura em Computação. Disponível em: https://claretiano.edu.br/graduacao/computacao. Acesso em: 02 set. 2020.

Contreras, J. (2012). A autonomia de professores. $2^{\text {a }}$ ed. São Paulo: Cortez.

Gauthier, C. et al. 2013. Por uma teoria da pedagogia: pesquisas contemporâneas sobre o saber docente. $3^{\mathrm{a}}$ ed. Ijuí: UNIJUÍ.

Gil, A. C. (2002). Como elaborar projetos de pesquisa. $4^{\mathrm{a}}$ ed. São Paulo: Atlas.

Kohler, M. J., Mishra, P. 2008. Introducing TPCK. In J. A. Colbert, K. E. Boyd, K. A. Clark, S. Guan, J. B. Harris, M. A. Kelly \& A. D. Thompson (Eds.), Handbook of Technological Pedagogical Content Knowledge for Educators (pp. 1-29). New York: Routledge.

Ifba. (2015). Projeto Pedagógico de Curso - Licenciatura em Computação. Disponível em: $\quad$ https://portal.ifba.edu.br/ead/cursos/licenciatura/computacao/documentos /licenciatura_computacao_ead_final_fev_15.pdf, Acesso em: 02 set. 2020.

Iffar. (2014). Projeto Pedagógico de Curso - Licenciatura em Computação. Disponível em: https://www.iffarroupilha.edu.br/projeto-pedagógico-de-curso/campus-santoaugusto. Acesso em 02 set. 2020.

IFSul. 2018. Projeto Pedagógico de Curso - Licenciatura em Computação. Disponível em: http://intranet.ifsul.edu.br/catalogo/curso/120. Acesso em 02 set. 2020.

Schön, D. (1992). Formar professores como profissionais reflexivos. In: NÓVOA, A. (org.). Os professores e sua formação. Lisboa: Dom Quixote.

Tardif, M. (2012). Saberes docentes e formação profissional. 14 ed. Petrópolis/RJ: Vozes.

Tardif, M. (2000). Saberes profissionais dos professores e conhecimentos universitários: elementos para uma epistemologia da prática profissional dos professores e suas consequências em relação à formação para o magistério. In: Revista Brasileira de Educação. Jan/Fev/Mar/Abr. No 13.

Ufba. 2010. Projeto Pedagógico de Curso - Licenciatura em Computação. Disponível em: https://blog.ufba.br/liccomp/. Acesso em 02 set. 2020.

Ufsm. (2015). Projeto Pedagógico de Curso - Licenciatura em Computação. Disponível em: https://www.ufsm.br/cursos/graduacao/educacao-a-distancia/computacao/ projeto-pedagogico. Acesso em 02 set. 2020.

Ufpr. (2014). Projeto Pedagógico do Curso de Licenciatura em Computação. Disponível em: https://profjefer.files.wordpress.com/2014/02/ppc-liccomputacao2016-palotina1.pdf. Acesso em 02 set. 2020 